\title{
Disposal of tailings and the mining industry perspective: a case study of the Cuiabá Mine
}

\author{
MFM Gomes AngloGold Ashanti, Brazil \\ JGM Filho AngloGold Ashanti, Brazil \\ JA Pinheiro AngloGold Ashanti, South Africa \\ C Crystal SRK Consulting (Canada) Inc., Canada
}

\begin{abstract}
One of the methods that has been studied for the disposal of tailings by the mining industry is dry stacking. Several studies have indicated that the use of filtered tailings is feasible under certain technical and operational conditions. The requirements for deposition, and characterisation of the tailings properties, must be obtained through a wide range of field and laboratory tests. These parameters are key to determining the behaviour of the material during the dewatering process, the optimum moisture content and the maximum density of the tailing cake, as well as the physical and environmental stability of the projected geotechnical structure. The operational aspects related to the handling of the material are also vital to determine the placement of the filtered tailings on the facility.

In addition, the advantages with respect to water consumption, reduced and/or flexible stack footprints and geometries, seepage control requirements, closure/reclamation costs and public perception of risk can result in dry stacking being selected as an economically beneficial alternative, particularly if life-of-mine risks and costs are appropriately considered. As with any conventional tailings management approach, careful and diligent planning, engineering and operational controls, quality assurance/quality control (QA/QC), instrumentation and monitoring are required to manage risks and uncertainties.
\end{abstract}

This paper presents the criteria that need to be evaluated in the evaluation of filtered tailings as a business case, based on the experience of the authors developing such projects within the minerals industry.

Keywords: dry stacking, mining industry

\section{Introduction}

Recent accidents involving dams containing mine tailings and industrial waste have been drawing attention to these structures, mainly because accidents are growing in number with the increase of industrial production. In this sense, waste management is becoming one of the criteria by which the socioenvironmental performance of companies is judged.

In order to minimise environmental impacts and improve safety and performance aspects of geotechnical works, there is concern about how to dispose of mining waste optimally. The AngloGold Ashanti Cuiabá Mine, located in Sabará, Brazil, developed a feasibility study of dry tailing stacking by filtering in a tropical climate region with rainfall more than $1,000 \mathrm{~mm}$ per annum. The Cuiabá Mine operates underground mining activities. The ore crushed underground is lifted to the surface and goes to secondary crushing and grinding. After grinding, the ore goes to flotation. After flotation, the concentrate is filtered and sent by cable car to the Queiroz metallurgical plant in Nova Lima, Brazil, to complete the process. The current operation of tailing at the Cuiabá Mine consists of two different disposal methods. Tailings first pass through a cyclone process, with the overflow going to a thickener and then pumped to a conventional dam. This tailings dam is located within a natural valley and has a wall of compacted soil with successive downstream raising. The thick portion from the underflow process is deposited in dewatering cells and then transported by truck and stacked inside 
an old open pit mine. Alternatively, all tailings may not be processed in the cyclone and may be hydraulically disposed of directly into the tailings dam.

In view of these new constraints and perspectives, a proposal for the evaluation of the implementation of alternative methodologies for tailings disposal, based on a technological characterisation of materials involving field and laboratory tests, becomes imperative to quantify the cost-benefit ratio of the future of tailings disposal. This evaluation should consider engineering techniques for the reconceptualisation of tailings disposal operations, developing alternatives to the current situation aiming at environmental, social and economic gains over the life of the mine. For this, geotechnical and technological alternatives must be considered, in compliance with current environmental legislation in Brazil and its updates throughout the life of the project. The application of filtered tailings disposal at mining operations worldwide is a potential alternative to conventional tailings disposal (Lara et al. 2013).

Several parameters should be considered for the conceptualisation and selection of the available alternatives for dewatering plant and tailing disposal:

- Geotechnical characterisation of tailings.

- Topography of the terrain and climatic conditions.

- Location limitations - existing infrastructure, utilities available area and zone of influence.

- Methods of disposal - hydraulic arrangement, disposal of dewatered material and co-disposition with waste rock.

- Waste dewatering methods - natural dewatering, cycloning, thickening and filtration.

- Materials handling/transport - pipe (pumping), belt conveyor and trucking.

These aspects are discussed in the following sections. The data and information are from the Cuiabá Mine project.

\section{Geotechnical requirements of the tailings}

The main parameters for the study are obtained through field and laboratory tests. The extent of these investigations is defined between the designer and the owner, depending on the quantity and type of samples available.

During the studies and projects, the first tests are carried out in the laboratory, highlighting:

- Full gradation analyses.

- Atterberg limits.

- Normal and modified Proctor.

- Permeability.

- Direct shear.

- Triaxial.

- Oedometer.

The full gradation analyses (Figure 1), together with the Atterberg limits and the permeability, are essential to define the behaviour of the material during the filtration process. A typical range of gradation results are presented in Figure 1. Normally, materials with good filtration performance predominate in the sandy silt range, with less than $10 \%$ clay, non-plastic and higher permeability when they are not densified. However, materials with higher clay fines content can generally be dewatered with less efficiency. Consideration should be given to the potential for the tailings properties to vary over the life-of-mine (LOM) as different underground zones are mined through. Therefore, periods of less efficient filtering should be anticipated. 


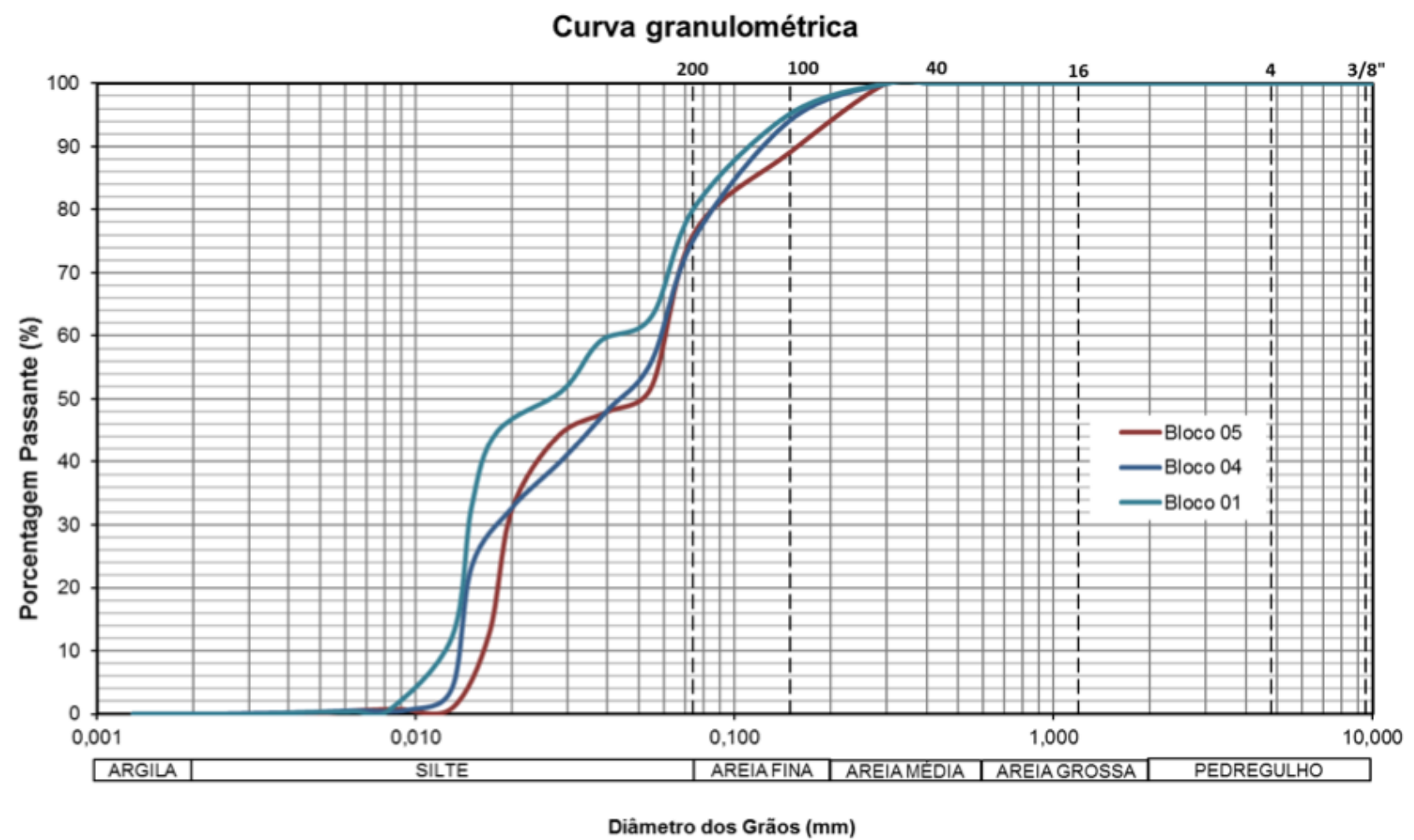

Figure 1 Full gradation analyses of samples of the field trial at Cuiabá Mine (Walm Engenharia Tecnologica Ambiental 2018)

The maximum dry density and optimum moisture content is obtained through the standard and modified Proctor testing in accordance with ASTM D 698 (ASTM International 2012a) and ASTM D 1557 (ASTM International 2012b). These tests, along with consideration of minimum and maximum void ratios, are essential to define the compaction specifications and help evaluate the equipment that will work in the spreading and compaction of the material to specified densities required in structural and non-structural zones.

The optimum geotechnical (or gravimetric) moisture content is a key parameter in evaluating the requirements of the dewatering plant, mainly the type and quantity of filters. The requirements for moisture condition for appropriate compaction, to meet specifications, should be compared to both the 'target' moisture content promised by equipment suppliers based on bench-scale dewatering tests and the actual, day-in day-out, 'achievable' moisture contents. The 'achievable' moisture content should be benchmarked against field-scale operations of similar equipment performance operating under similar conditions. Table 1 presents select results for laboratory density testing of tailings samples for field trials at the Cuiabá Mine.

Table 1 Laboratory density of tailings for field trial at Cuiabá Mine (Walm Engenharia Tecnologica Ambiental 2018)

\begin{tabular}{lcccccc}
\hline Sample & $\begin{array}{c}\text { Real } \\
\text { density } \\
\left(\mathbf{g} / \mathbf{c m}^{\mathbf{3}}\right)\end{array}$ & $\begin{array}{c}\text { Minimum } \\
\text { index of } \\
\text { void }\end{array}$ & $\begin{array}{c}\text { Maximum } \\
\text { index of } \\
\text { void }\end{array}$ & $\begin{array}{c}\text { Optimum } \\
\text { moisture } \\
\text { content }(\%)\end{array}$ & $\begin{array}{c}\text { Dry } \\
\text { density } \\
\left(\mathbf{g} / \mathbf{c m}^{3}\right)\end{array}$ & $\begin{array}{c}\text { Atterberg } \\
\text { limit }\end{array}$ \\
\hline Bloco 1 & 2.87 & 0.90 & 1.4 & 14.55 & 1,758 & No plastic \\
Bloco 5 & 2.80 & 0.82 & 1.23 & 13.8 & 1,789 & No plastic \\
\hline
\end{tabular}

Permeability after compaction defines the internal drainage system. It also helps to understand the amount of water that infiltrates and flows superficially during rainfall. 
The oedometric (consolidation) tests contribute to understanding the material consolidation and drainage behaviour of the stacked materials, key to understanding the potential for self-weight consolidation and need for additional pore pressure relief if very low permeability materials are stacked too rapidly. The consolidation behaviour will inform the rate-of-rise limitations during operations. It is very important to set the stack-raising rate to preclude the potential for static liquefaction. Additional laboratory testing results filtered tailings for field trials at Cuiabá are presented in Table 2.

Table 2 Laboratory characterisation of the tailings field trial at Cuiabá Mine (Walm Engenharia Tecnologica Ambiental 2018)

\begin{tabular}{lcccccc}
\hline Sample & $\begin{array}{c}\text { Over-consolidation } \\
\text { ratio }\left(\mathbf{m}^{2} / \mathbf{s}\right)\end{array}$ & $\begin{array}{c}\text { Initial } \\
\text { index of } \\
\text { void }\end{array}$ & $\begin{array}{c}\text { Final } \\
\text { index of } \\
\text { void }\end{array}$ & $\begin{array}{c}\text { Measured } \\
\text { permeability } \\
\mathbf{( c m} / \mathbf{s})\end{array}$ & $\begin{array}{c}\text { Calculated } \\
\text { permeability } \\
\mathbf{( c m} / \mathbf{s})\end{array}$ & $\begin{array}{c}\text { Maximum } \\
\text { tension } \\
\mathbf{( k P a )}\end{array}$ \\
\hline Bloco 1 & $4.46 \mathrm{E}-05$ & 0.74 & 0.47 & $1,92 \mathrm{E}-04$ & $1,09 \mathrm{E}-05$ & 61 \\
Bloco 5 & $4.61 \mathrm{E}-05$ & 0.79 & 0.63 & $2,65 \mathrm{E}-06$ & $8,04 \mathrm{E}-06$ & 137 \\
\hline
\end{tabular}

Strength testing is essential for the understanding of the drained and undrained geotechnical behaviour of the structure. During the design of the project, the direct shear, triaxial drained and non-drained tests provided the complementary parameters for stability analysis of both the potential dry stack as well as the underlying existing slurry tailings facility.

In addition to the collection of undisturbed samples, piezometer cone penetration testing (CPTU) allowed analysis of the behaviour of material with and without the presence of water, identifying susceptibility to liquefaction and helped in the consolidation study.

In the case where dry stacking is proposed over existing slurry impoundments, it is also very important to define the potential response of the underlying impoundment to the future static and dynamic applied loads, particularly with respect to consolidation, drainage and whether the tailing has contractile or dilating behaviour based on the results of CPTU.

As a way of complementing information, and especially in the phase of feasibility and design for construction, field trials are very important. The objective is to evaluate/validate the behaviour of tailings simulating operating conditions under the follow aspects:

- Tailings capacity to reach the expected compaction conditions when spread and densified with the passage of conventional equipment and with the remaining moisture content of the filtration process and with higher humidity variations (Figure 2).

- Assessment of tailing handling to achieve design conditions.

- Definition of the best combination of layer thickness versus compacting to achieve the project compaction conditions.

- Collection of undisturbed samples for the determination of the geotechnical characteristics of the tailing, comparing the field with the project data (Figure 3).

- Collection of deformed samples at different points to evaluate the moisture content in different stages of the construction process.

From a technical specification made by the consultant, the area is prepared; the material is loaded at the point of origin, transported and arranged. At this point, the moisture content is checked. If it is below target, it is wetted. If it is above, it is aerated. The material is spread according to predefined layer thicknesses. Immediately after spreading, field tests and laboratory samples are collected. An experienced consultant should carry out this work. 


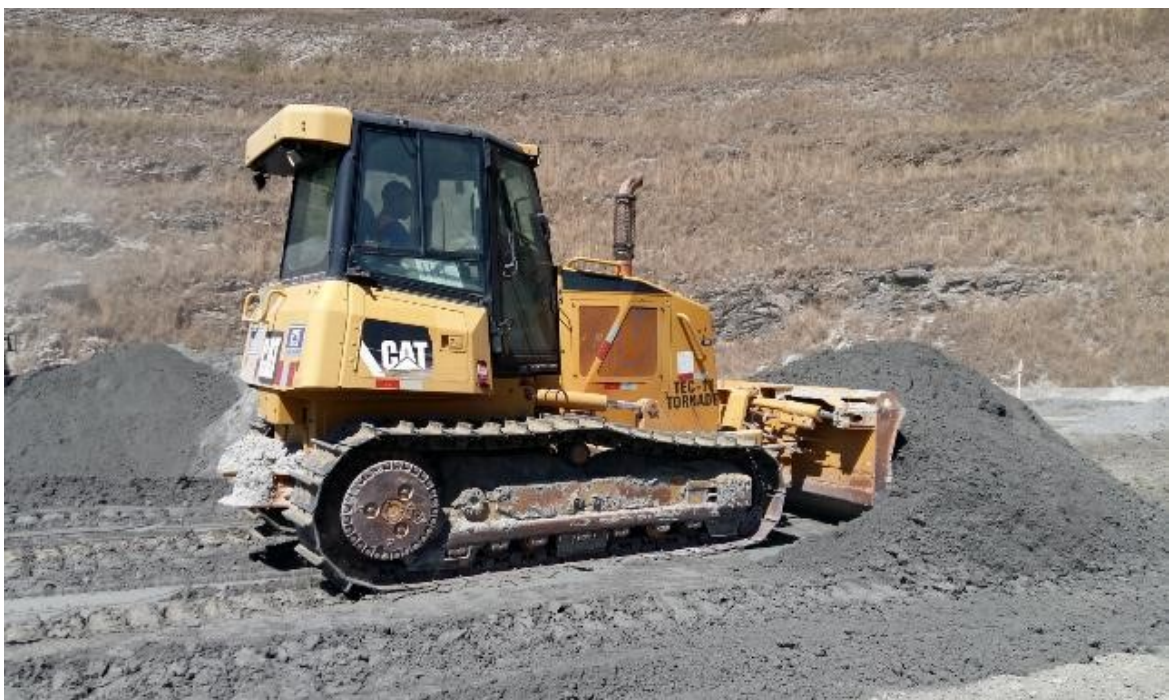

Figure 2 Spreading the material with a bulldozer (BVP Engenharia 2017)

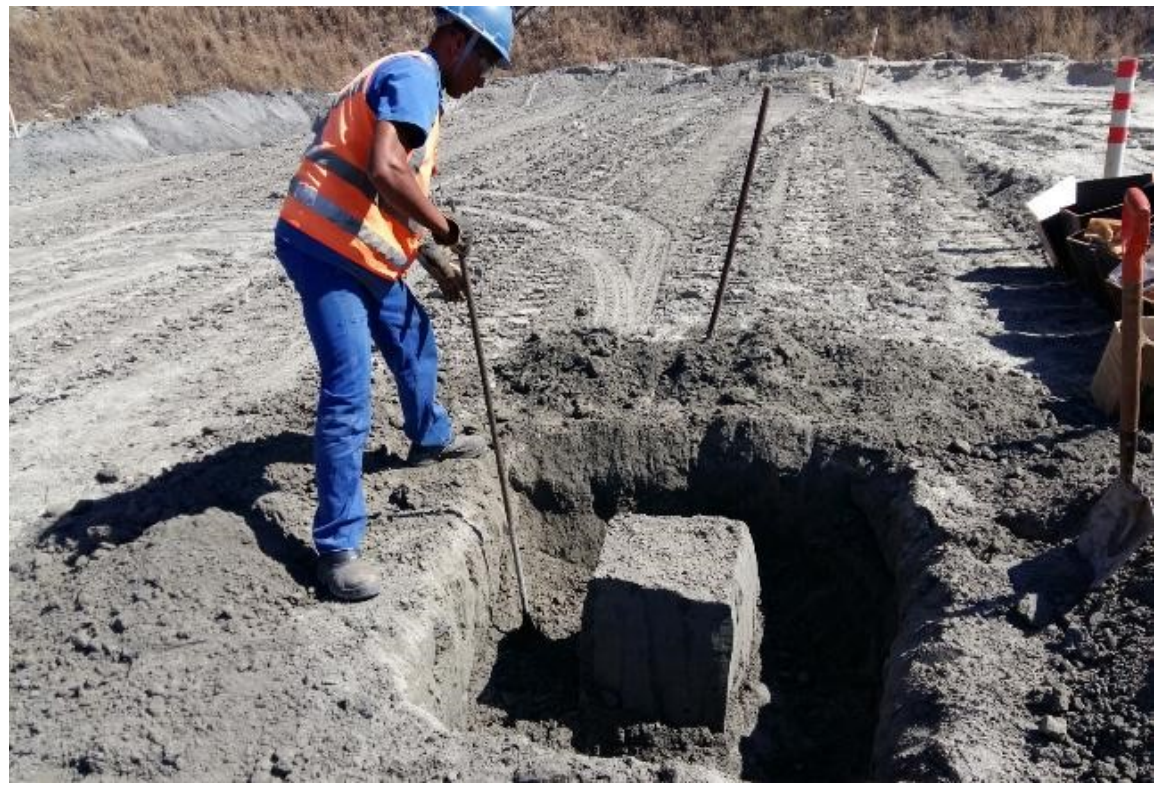

Figure 3 Undisturbed sample collected in the field (BVP Engenharia 2017)

\section{$3 \quad$ Tailings disposal methods}

In addition to the geotechnical properties, the topography of the site will also define the tailings disposal approaches. With mountainous relief similar to that at the Cuiabá Mine, there is the possibility of stacking the material in valleys - in the form of a canyon or in a freestanding pile format. Other preliminary geometries considered included:

- Dry stack on top of existing dams (Figure 4(a)).

- Dry stack in a new location (Figure 4(b)).

- Co-disposition of waste rock and dry tailings (Figure 4(c)). 
a)

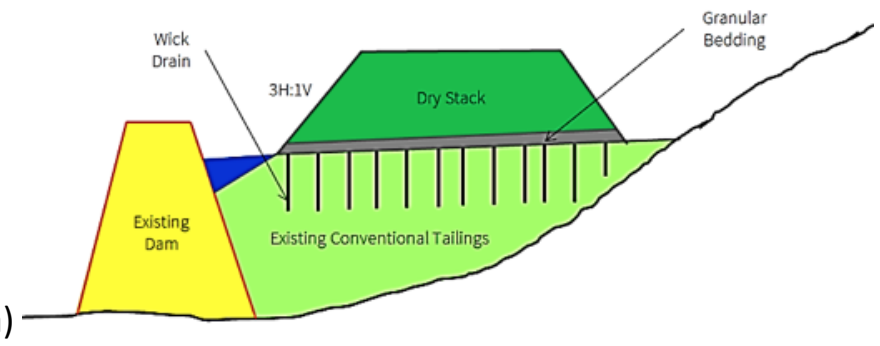

b)

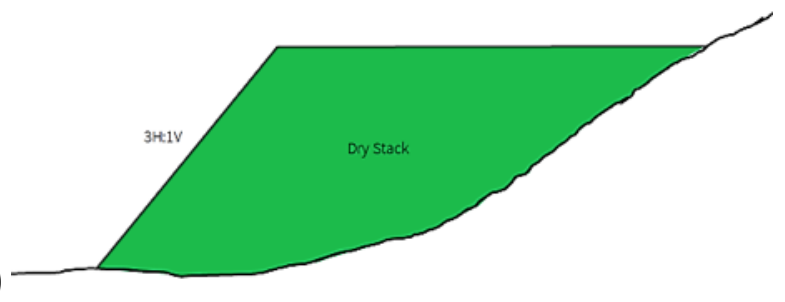

c)

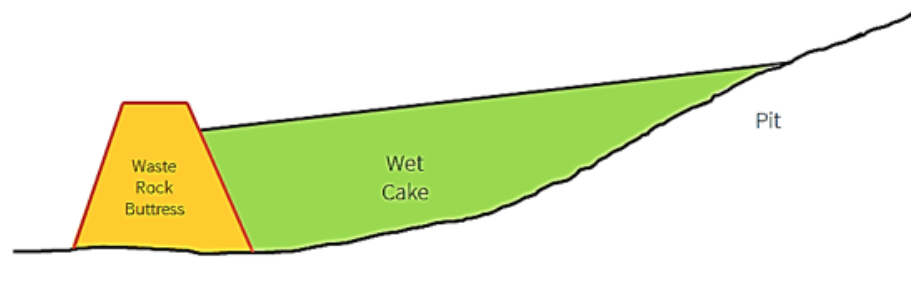

Figure 4 Tailings disposal methods in valleys (Hatch Engenharia e Consultoria 2017)

Approaches that reduced or eliminated dependency on a retaining structure dam were preferred. According to the aforementioned points, the options considered further included the dry stack in a new location (Figure 4(b)), on an existing dam (Figure 4(a)), with buttressing, or in a co-disposal arrangement with waste rock (Figure $4(c))$. In the case of the Cuiabá Mine, the study indicated that the most economic option was a combination of buttressing of the existing facility and potentially continuing with filling overtop of the existing facility, pending performance during field trials, as shown in Figure 5. There was already a dam in the valley and the geotechnical tests indicated the possibility of using co-disposition of tailing and waste rock for raising this structure.

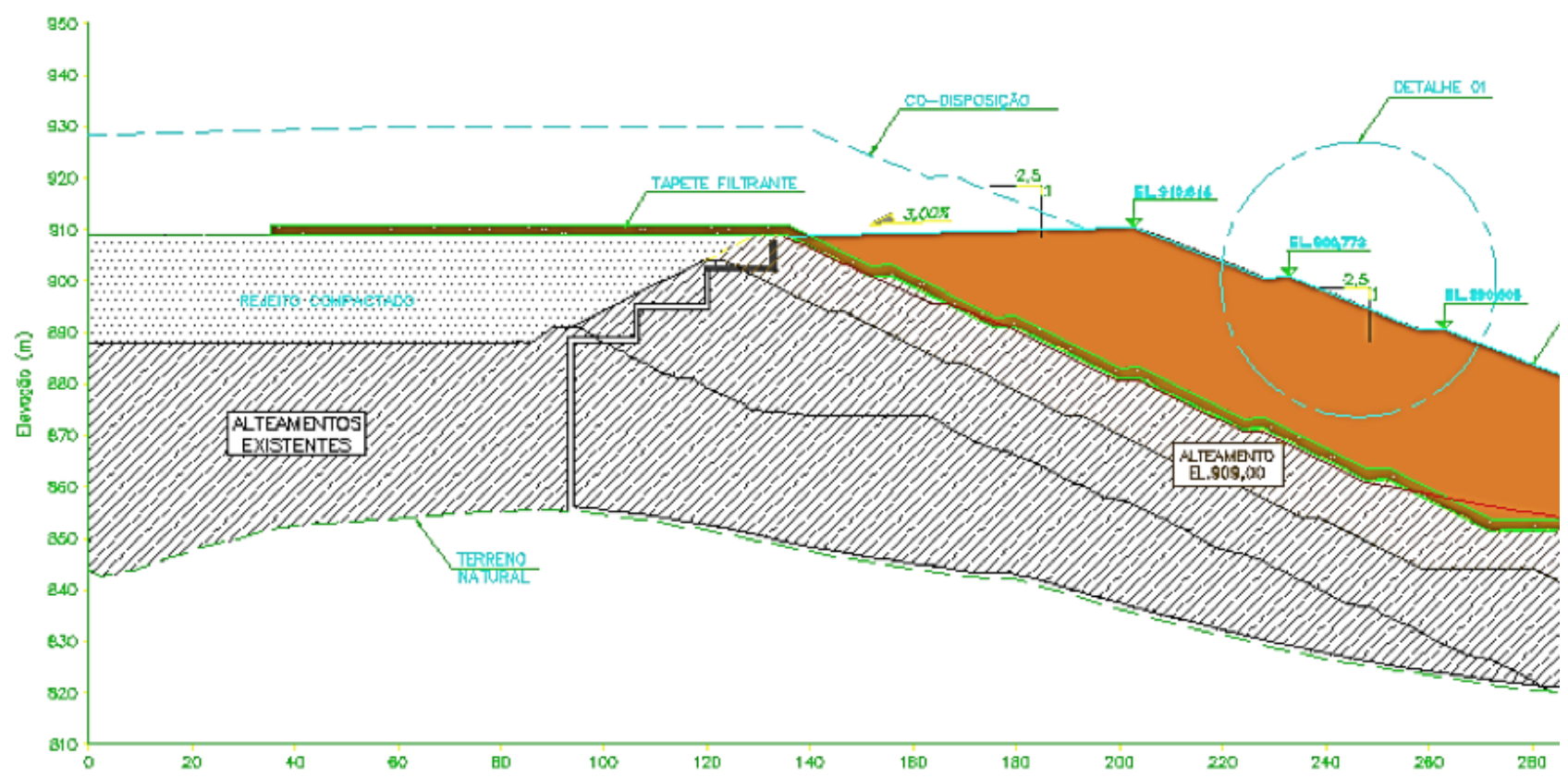

Figure 5 Typical section of Cuiabá dry stacking (Walm Engenharia Tecnologica Ambiental 2018) 


\section{$4 \quad$ Dewatering options}

The selection of the appropriate tailings dewatering technology depends on an analysis of the specific circumstances of each project, such as location, climate, topography and the geotechnical and chemical properties of the tailings.

Consideration was given to a variety of dewatering approaches including pressure filtration (plate-and-frame filter presses), horizontal belt filters and vacuum ceramic disc filters, as is described in the following section.

\subsection{Filter presses}

Pressure-filtration is one of the most used solid-liquid separation machines for discontinuous cake filtration and for dewatering of difficult-to-filter suspensions. Filtration takes place discontinuously and as a driving force; a pump applies overpressure. A filter press is made up of a sequence of filter plates, typically made from polymer, forming contained cloth or wire filter elements. The filter plates are mounted on a supporting frame between the head and the end piece and are pressed together for sealing. Slurry is forced into the filter chambers, under pressure, by means of a pump and the filtrate passes through the filter cloth. The retained solids form a filter cake, and filtration proceeds until each chamber is filled with cake.

A disadvantage of the frame filter press is the solids discharge, by both manual or automated opening and breaking the cake out of the frames. As more automated operation of cake discharge was introduced, neighbouring recessed filter plates that face each other to form the filter chamber with a filter cloth stretched over each plate became more common. As discharge of the cake can be executed more simply than from simple frame filter presses. Regardless, the process limitations include minimum and maximum filter cake thickness (i.e. of a certain weight) to ensure that the cake falls out by gravity. But not so thick as to require excessive retention (or cycle times) for dewatering of the material between the cloths, filter cake formation against the cloths require a balance of cycle time versus filtration efficiency. Many other factors including air-blow and wash cycle scheduling and duration can all differentiate the efficiency of the filter presses. A key limitation can also be limitations on the achievable percent solids by weight of the slurry coming out of the thickeners, upstream of the filters and in general, the entire process must be considered holistically.

A further development of a chamber filter press is the membrane filter press, which allows the filter cake in the filter chamber to be squeezed from one side by a rubber membrane. The filter and membrane plates alternate with each other. The advantages of this design can be that the feed pressure of the slurry can be kept low and that a high-pressure pump is not needed since the filter cake can be uniformly compressed by the membrane. However, a trade-off evaluation between cycle-time, cost and efficiency can determine if the additional 'squeeze' is an advantage or disadvantage given project constraints and tailings characteristics. To summarise the trade-off:

- With respect to the capital expenditure (CAPEX) / operational expenditure (OPEX) comparison, filter presses are generally more efficient and can achieve a high solids content in a reduced cycle time. However, the automated operation requires a large number of components (valves and instruments) all needing maintenance; cleaning and flushing that ensures feed lines remain operational.

- Many components and peripheral equipment may require high maintenance efforts and high spare parts demand.

Pressure filtration can therefore be a high CAPEX and OPEX approach. But if the efficiency is considered over LOM, is generally a lower OPEX option than belt or vacuum filtration options, depending on other operational factors, including location, climate and operational efficiencies.

\subsection{Belt filter}

The belt filter type is a continuously or quasi-continuously operating horizontal vacuum filter. Basically, a belt filter consists of a filter cloth that is moving continuously or with interrupted motion over several rollers. 
With respect to construction and function, two main types of belt filters exist. The oldest variant is the conveyor belt or carrier belt type, which is the relevant version for applications in tailings filtration. The conveyor belt, usually a reinforced rubber belt with grooves and slots for filtrate drainage, moves around the rollers to support and convey the filter belt. The rubber belt slides over a vacuum box, which collects the filtrate. Different from this version, the tray type consists of a series of trays underneath the cloth belt. The trays are connected to the vacuum and can either be transported with the cloth, up to a certain position where they return to the starting position, or can be fixed while the cloth belt moves intermittently. Both operation methods of the tray type require that the vacuum is periodically cut-off and applied again to allow for return transport of the trays or for the intermittent cloth transport.

On belt filters, the filtration process takes place in the direction of gravity along the horizontal cloth belt and typically includes filter cake formation, filter cake washing and cake dewatering by air. Discharge of the filter cake is performed by reversing the cloth belt around a roller of small diameter and can be supported by means of a scraper and/or a reverse flow of compressed air. After cake discharge, the filter cloth can be washed from both sides.

Belt filters are applied in many industries - from chemicals to mineral processing - and are especially suited for easy filtering products that require intensive cake washing, since the washing medium can be applied on the filter cake from the top as a pool. Typical filter sizes range from $1 \mathrm{~m}^{2}$ up to over $100 \mathrm{~m}^{2}$. More detailed information on belt filters can be found in Sutherland (2005) and Wakeman and Tarleton (2006).

With respect to the CAPEX/OPEX comparison, the following features of belt filters shall be mentioned:

- Large space demand as a consequence of a large footprint (per square metre filtration area) and relatively low specific solids throughput making many filter units necessary to ensure target solids performance.

- High amount of sealing water required to provide for secure sealing of the rubber belt.

Potentially lower CAPEX, but higher OPEX (if LOM costs including moisture conditioning requirements in structural zones) are fully considered.

\subsection{Ceramic disc filter}

A special type of disc filter uses micro pore ceramic sectors instead of steel covered with filter cloth.

Ceramic capillary action disc filters are continuously operating units that are mainly used in high-tonnage applications for dewatering relatively free-filtering suspensions, such as mineral and metal concentrate slurries. This filter technology is based on high-tech sintered alumina membranes, which have uniform micro pores to create capillary action (Ekberg \& Woitkowitz 1988; Lotzien et al. 1988; Ekberg \& Haartti 1993). The performance of the filters is mostly based on the special properties of the ceramic filter medium and the capillary phenomenon, due to which the filters are energy saving and durable under severe conditions, thus providing an excellent alternative for conventional disc filters with low cake moistures and high capacities (Outotec 2010).

When submerged in the slurry pool, capillary action assists the uptake of liquid through the pores of the filter. For the filter (as opposed to the cake), we want the capillary pressure to be high, achieved by having a small pore diameter and strongly hydrophilic material - that is, ceramic. The action reduces the size of the vacuum pump required, resulting in reduced energy consumption. Referred to as 'capillary filtration', it can produce moisture contents that approach pressure filtration, and has found application on mineral concentrates (Cox \& Traczyk 2002; Concha 2014) as well as tailings dewatering.

Cake formation (Figure 6(a)) takes place on the disc segments as they move through the slurry basin, and the time available for this stage depends on the rotation speed of the disc and the height of the slurry level in the basin. As soon as the segment rises from the slurry, dewatering of the cake (Figure 6(b)) begins. The available drying time is usually an operating constraint of the filter unit, and also this depends on the rotation speed and slurry level. Cake discharge (Figure 6(c)) occurs after the dewatering stage due to blade or wire 
scrapers installed on both sides of each disc or to a fast pressurized air pulse (snap blow), as is the case in conventional disc filters. Just before the segments are immersed into the slurry again, there may also be a short back flow washing stage for refreshing the filter medium and thus ensuring good cake formation and dewatering results during the next cycle.
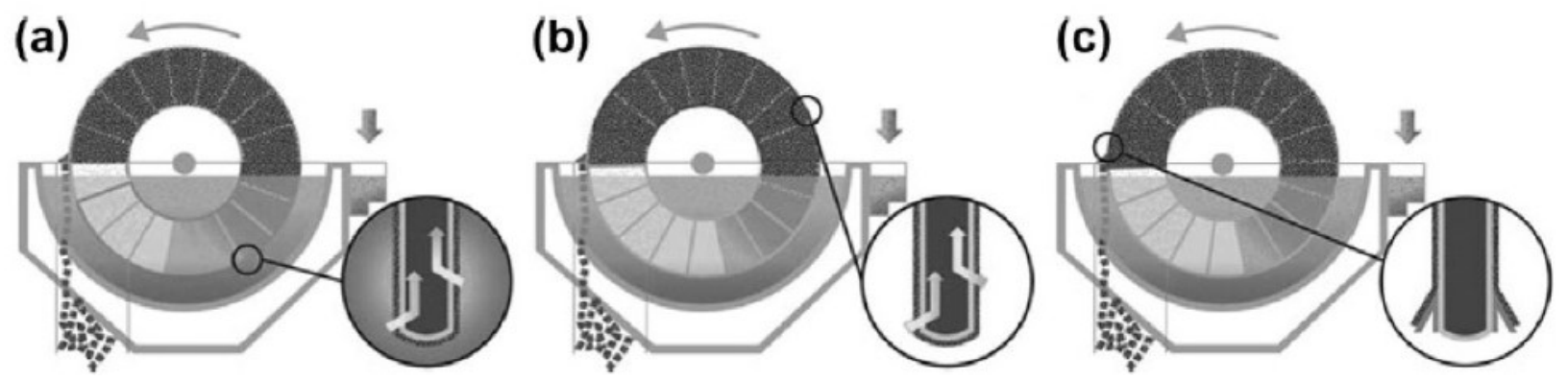

Figure 6 Cake formation: (a) cake dewatering; (b) cake discharge; and (c) stages in rotary vacuum disc filters (Outotec 2010)

The permeability of the ceramic plates is maintained by two different washing actions. During concentrate production, a short back flushing of each ceramic plate sector is performed once after cake removal during each revolution of the disks. Long-term disk permeability is maintained by using separate washing periods in which the filter is filled with pure water and ultrasonic cleaning is used during the back flushing of water or diluted acid through the ceramic plates.

The timing of the washing periods is the key factor that affects the cumulatively achievable maximum production capacity. If washing is done too often, or at a time when it is not really necessary, then the time spent in washing periods means a loss of cumulative production capacity. Unnecessary washing might also mean extra washing chemical costs. On the other hand, if washing is done too seldom, or it is not done in situations where it would be really beneficial, then capacity is lost, because the filter is operating at too low a disk permeability.

Ceramic rotating disk filters offer many advantages over traditional rotating disk filters. They require much less maintenance and their energy consumption can be up to $90 \%$ lower than that with traditional disc filters, which together means lower operating costs per produced capacity.

\subsection{Conditions for use of a ceramic disc filter}

Using a disc filter for tailing operations requires that:

- The clay content in the solids is low.

- Mine backfill is processed.

- The tonnage is $>50 \mathrm{t} / \mathrm{hr}$.

- The equipment is energy efficient.

- There are no space constraints.

- The equipment is of low maintenance.

- The amount of flocculent present is low.

- Operational costs are economical.

\subsection{Process requirements and equipment sizing}

Benchtop test work was performed on samples of tailings slurry to identify the slurry characteristics according to the filtration requirements. Ceramic filtration bench-scale test work was undertaken using a small filter element and a leaf for simulating a disc section within the same properties and structure of the 
full-scale filter disc. The focus was on estimating the dewatering properties of the slurry associated with feeding and optimum moisture content of the dry cake to obtain the maximum compaction degree and dry density from the compacted material.

The geotechnical test work identified a target moisture of $14 \%$ (process definition). The slurry feed concentration is $62 \%$ (process definition), which corresponds with the classification (cyclone underflow) and thickeners underflow from the backfill station of the process plant. The key findings of the filtration test work are shown in Table 3.

Table 3 Filtration test work results (ceramic disc filters) - Cuiabá Mine

\begin{tabular}{lccccccc}
\hline Test no. & $\mathbf{1}$ & $\mathbf{2}$ & $\mathbf{3}$ & $\mathbf{4}$ & $\mathbf{5}$ & $\mathbf{6}$ & $\mathbf{7}$ \\
\hline Slurry dry solids content (\%) & 62.22 & 62.22 & 62.22 & 62.22 & 62.22 & 62.22 & 62.22 \\
Slurry pH & 7.31 & 7.31 & 7.31 & 7.31 & 7.31 & 7.31 & 7.31 \\
Cake forming time (s) & 10 & 13 & 21 & 8 & 10 & 16 & 4 \\
Cake drying time (s) & 16 & 22 & 35 & 18 & 25 & 40 & 18 \\
Cake wash and dead time (s) & 4 & 5 & 9 & 4 & 5 & 9 & 8 \\
Cycle time (s) & 30 & 40 & 65 & 30 & 40 & 65 & 30 \\
Cake thickness (mm) & 10.5 & 12 & 15.5 & 9 & 10.2 & 11.5 & 5.3 \\
Cake moisture content (\%) & 15.1 & 14.7 & 14.8 & 14.4 & 13.9 & 14.3 & 12.7 \\
Filtration capacity & $2,053.33$ & $1,766.67$ & $1,505.64$ & $1,742.22$ & $1,440.00$ & $1,177.44$ & $1,040.00$ \\
(kg d.s./m ${ }^{2}$ h) & & & & & & & \\
\hline
\end{tabular}

The process plant is designed for an instantaneous throughput of $232 \mathrm{t} / \mathrm{hr}$ (dry solids) with the required availability in excess of $85 \%$. The project life is 12 years. Combining these inputs with the test work results, it is possible to estimate the key sizing parameters of the main process equipment for dewatering Cuiabá tailings using ceramic disc filters (Table 4).

Table 4 Filtration equipment requirements (ceramic disc filters) - Cuiabá Mine

\begin{tabular}{lc}
\hline Item & Data \\
\hline Normal feed rate nominal (tph) & 232 \\
Project factor & 1.2 \\
Project feed rate (tph) & 278 \\
Slurry dry solids content (\%) & 62 \\
Unit filtration rate $\left(\mathrm{t} / \mathrm{hr} / \mathrm{m}^{2}\right)$ & 1.05 \\
Calculated filtering area $\left(\mathrm{m}^{2}\right)$ & 265 \\
Area per filter ( $\mathrm{m}^{2}$ ) & 100 \\
No. of filters - calculated & 2.6 \\
No. of filters - standby & 1 \\
No. of filters - adopted & 4 \\
\hline
\end{tabular}

The quality of the filtered solution resulting from the filtration test work was also observed. There were no losses of solids within filtrate (content of filtrate solids: $0.001-0.005 \mathrm{~g} /$ litre) as shown in Figure 7 . Therefore, it can be used to reduce water consumption in the processing plant. 

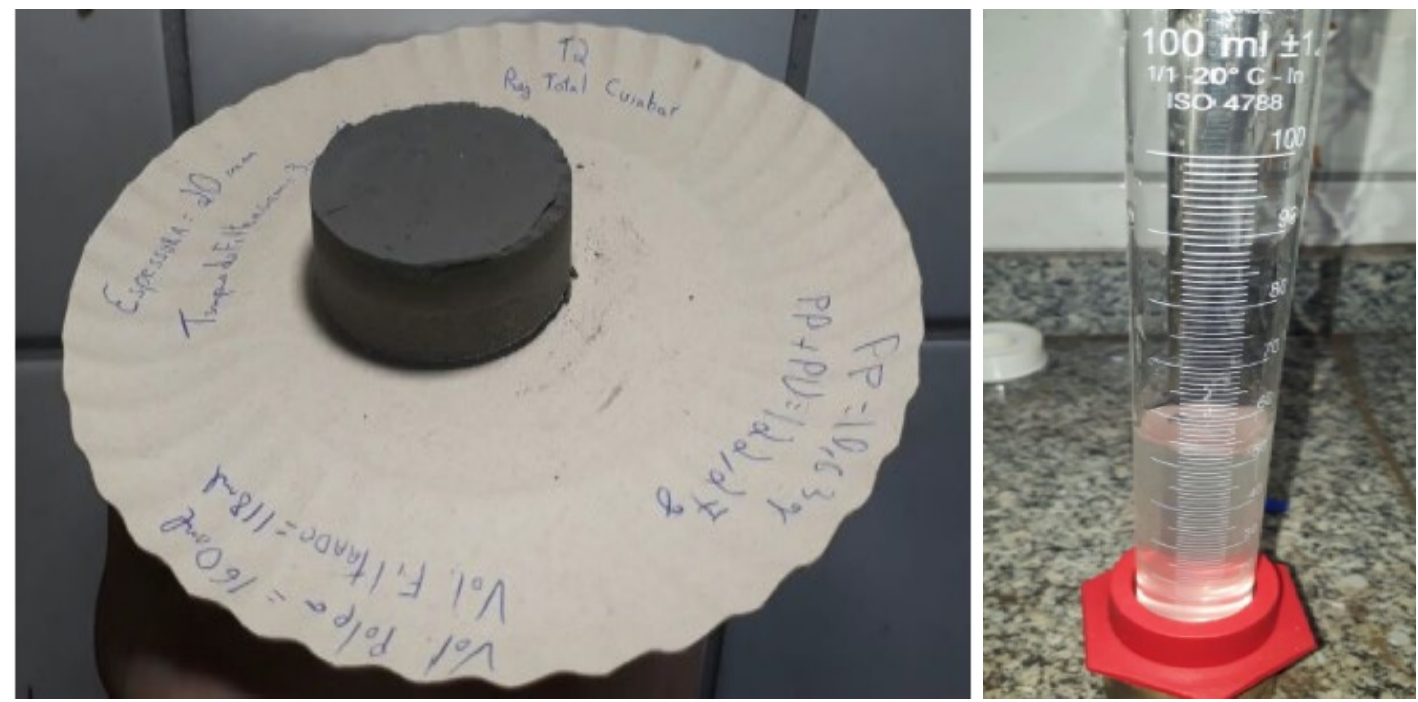

Figure 7 Cake and the turbidity of water after ceramic filtration test with Cuiabá tailings (Testwork Desenvolvimento de Processos 2017)

\section{$5 \quad$ Tailings handling and placement}

The consistency of the tailings (such as mud or wet mass) directly influences its behaviour and handling. Filtered material can be transported by conveyor belt or truck, depending on the amount of material to be transported. Larger volumes may justify the choice of a conveyor belt, as it reduces operating costs over the years and outweighs the high initial investment. Regardless, consideration should be given to conveyance distance and the potential for filtered tailings to liquefy during transport. For smaller scale operations, trucking is generally more cost-effective. In the case of this study, the throughput is 5,000 tpd, which justifies the use of trucks.

The dry stacking arrangement can also be shared with other materials in the same area, which is called co-disposal. The current co-disposal arrangement, of dewatered (by pond settling) tailings and waste rock at Cuiabá is shown in Figure 8.

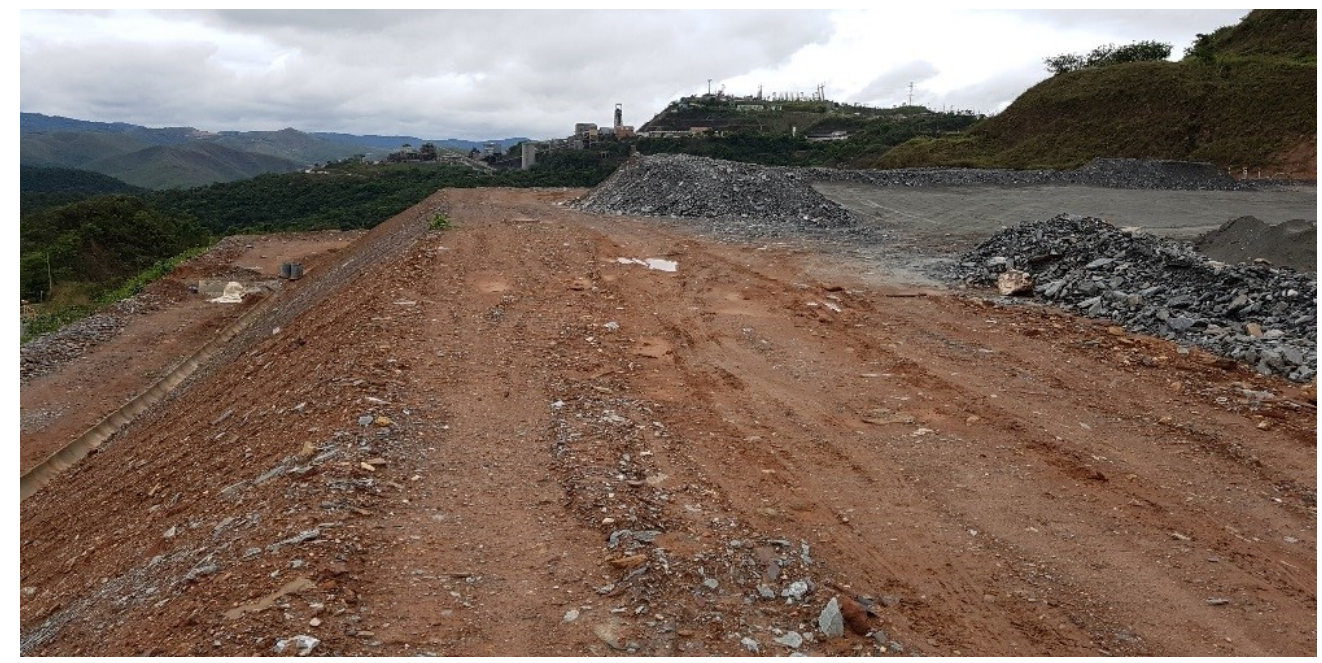

Figure 8 Co-disposal of tailing and waste at the old open pit Cuiabá Mine

In the disposal of the dry material, the structure is uniformly raised. Spreading is usually done with a bulldozer, which ensures the first stage of compaction. This operation should follow the project compaction specifications in relation to the moisture content of the material and equipment passes, guaranteeing the minimum degree of compaction required in the project and formation of the stockpile with the appropriate 
geotechnical stability. If it is necessary to increase the compactness, as well as to shed precipitation, a smooth roller can be used on a daily basis on the operating deck.

To confirm the information that defines the mode of operation, a field trial is recommended. This work should have a boundary condition as close as possible to day-to-day operations. Section 2 provides details of the procedure and tests.

\section{Premises for the design of the dry stacking system}

In order to become technically feasible, environmentally friendly and not cause the stoppage of the production, the project should contemplate:

- Additional points for the disposal of filtered material on rainy days.

- Surface water controls and control of sediment carried during the operation. For places of high rainfall including high intensity and short duration (as at the Cuiabá site), during the construction of the stockpile it is necessary to consider provisional sumps for retention of sediments carried as an environmental control measure.

- Particularly during the 'ramp up' phase of the filter plant, there is often a need for stoppage and operational adjustments. These interventions have a short duration but they impact other production processes. In these moments, it is necessary to place the total tailings at a specific point prepared for this purpose, in the stockpile itself or in any other structure. This condition must be predicted in the project, but can generally be avoided if additional filtration units are planned such that there is always a spare unit if one or more units goes down. In the author's experience the need for an off-spec slurry impoundment can be avoided for operations $<10,000 \mathrm{tpd}$. There can be periods of slow-down in the initial start-up phase of a project where target throughputs have periodically not been achieved. This can be due to filtration efficiency issues and/or the need for maintenance or repairs and a lack of redundancy.

- Installation of dewatering with backup equipment. With regards to the sizing of equipment, especially the filters, it must be considered that several factors can influence their performances. Critical equipment must have a reserve installed to prevent production delays.

Filters often have low availability. During the project, it is necessary to consider repair time, loss of capacity filtering and the time needed to clean the plates, among other things. Because of these, the project considers a global availability factor of $70 \%$.

\section{Conclusion}

In general, the disposal of dry tailings, instead of conventional hydraulic disposal, reduces the volumes of geotechnical structures, with a subsequent reduction of associated risks and environmental impacts.

To achieve the geotechnical stability of a dry stack, compaction of the disposed material is essential. The moisture content of the treated mass is the key parameter to obtain the necessary point in the field. In this context, the required conditions can be obtained by filtering the pulp. Today, the industry presents a wide range of filter options for developing efficient systems.

With the technical characteristics properly studied, the tailings generated at the plant may prove to be suitable for being filtered and stacked dry with geotechnical and environmental safety. The laboratory process tests and pilot-scale will indicate the moisture content obtained from the filter cake. This value should be compared with the optimum moisture content obtained in the geotechnical tests.

The high costs of implementation and operation can make this technology appear unfeasible. However, not only economic issues must be considered. Aspects focused on the environmental impact of construction and operation, potential risk to community and environment may make the alternative of dry stacking feasible 
compared to the conventional method of constructing a new dam or raising an existing dam and the hydraulic disposal of the material.

The current trend is to ensure the continuity of the mining activity, but in a more technical and environmentally safe way, to ensure good relations between industry and society. Advances in tailings dewatering and dry stacking will greatly benefit the mining industry in the future.

\section{Acknowledgement}

We extend our thanks to AngloGold Ashanti for permission to publish the paper.

\section{References}

ASTM International 2012a, ASTM D698: Standard Test Methods for Laboratory Compaction Characteristics of Soil Using Standard Effort (12 $\left.400 \mathrm{ft}-\mathrm{lbf} / \mathrm{ft}^{3}\left(600 \mathrm{kN}-\mathrm{m} / \mathrm{m}^{3}\right)\right)$, ASTM International, West Conshohocken.

ASTM International 2012b, ASTM D1557: Standard Test Methods for Laboratory Compaction Characteristics of Soil Using Modified Effort (56,000 ft-lbf/ $\left.\mathrm{ft}^{3}\left(2,700 \mathrm{kN}-\mathrm{m} / \mathrm{m}^{3}\right)\right)$, ASTM International, West Conshohocken.

BVP Engenharia 2017, Relatório AA-100-BV-0498-201-RF-001 - Acompanhamento técnico das atividades de aterro experimental com rejeito total na Mina de Cuiabá.

Concha, FA 2014, 'Solid-liquid separation in the mining industry', Springer, Fluid mechanics and its Applications (series), vol. 105.

Cox, C \& Traczyk, F 2002, 'Design features and types of filtration equipment', in AL Mular, DN Halbe \& DJ Barratt (eds), Mineral Processing Plant Design, Practice and Control, vol. 2, Society for Mining, Metallurgy \& Exploration, Littleton, pp. 1342-1357.

Ekberg, B \& Haartti, J 1993, 'Capillary filtration - the harnessing of natural forces to serve the process industry', Proceedings of the XVIII International Mineral Processing Congress, The Australasian Institute of Mining and Metallurgy, Melbourne, pp. 1303-1308.

Ekberg, B \& Woitkowitz, S 1988, 'Cake-forming wet filtration without gas throughput with the new ceramic Ecosuc disc filters', Aufbereitungs-Technik, vol. 28, no. 4, pp. 193-196.

Hatch Engenharia e Consultoria 2017, Relatório de Projeto AA-134-HA-0497-267-RT-002 - Reconceituação de disposição de rejeito e Estéril da Mina de Cuiabá e CDS.

Lara, JL, Pornillos, EU \& Muñoz, HE 2013, 'Geotechnical-geochemical and operational considerations for the application of dry stacking tailings deposits - state-of-the-art', in RJ Jewell, AB Fourie, J Caldwell \& J Pimenta (eds), Proceedings of the 16th International Seminar on Paste and Thickened Tailings, Australian Centre for Geomechanics, Perth, pp. 249-260.

Lotzien, K, Jung, RG \& Janitschek, R 1988, 'Filtration without air throughput of filter material', Aufbereitungs-Technik, vol. 28, no. II, pp. 628-636.

Outotec 2010, Outotec Larox cc. product information brochure, Outotec, Espoo.

Sutherland, KS 2005, Solid/Liquid Separation Equipment, Wiley-VCH Verlag GmbH \& Co, KGaA, Weinheim, Baden-Württemberg.

Testwork Desenvolvimento de Processos 2017, Relatório técnico No 017-2017 - Testes de Processo do rejeito da Mina de Cuiabá e CDS.

Wakeman, RJ \& Tarleton, ES 2006, Solid/liquid Separation: Equipment Section and Process Design, Elsevier Science, Oxford.

Walm Engenharia Tecnologica Ambiental 2018, Relatório técnico AA-157-WA-0498-267-RT-006-Resultados dos ensaios de campo e consolidação dos parâmetros de projeto. 
